\title{
Hoist by Their Own Petard
}

A funny thing happened at ALA Midwinter. What's more, it was fascinating as well, for it was one of the loveliest examples of "communications dysfunction" I've ever seen. (Dysfunction: impaired or abnormal functioning.)

Librarians-information scientists-have always been concerned with the transfer of information. In recent times, this concern has been explicitly identified as constituting the major component of the profession's domain. Whether one interprets information to be the book, and discusses its transfer in terms of acquisitions, circulation, and interlibrary loan, or one interprets information to be datum, and discusses transfer in terms of access, retrieval, and transfer, the fact remains that information transfer is the area of concern of the information profession.

Yet, as is already evident from the paragraph above, the medium being used to relay the message, the unit which is basic to the process of information transfer, i.e., the word, is a fractious thing. One would think that informationalists would be among the most alert to this frailty of language; yet, though the problem has been addressed at great length by a great many, members of our profession have not been predominant among them. We, too, use words ever more loosely, violate structure ever more often, and transpose jargon ever more freely-unaware, and, apparently, uncaring that in the process we are vitiating the very foundation of our field.

And thus, at the Palmer House in Chicago, during a very balmy January Midwinter Meeting of the American Library Association, a select group of professional practitioners who had gathered together to work together found themselves caught in their own trap. They were unable to communicate! Information specialists-listening without hearing, reading without comprehending, talking without communicating.

It was almost frightening. "Network" concerns got defined in terms of the need for reimbursement for interlibrary loan. The phrases "data base interchange," "machine-readable record exchange," and "networking" were being used interchangeably, engendering damaging misconceptions. The distinction between "contract negotiation assistance" (which CLR will provide the Anable serials group) and "contracting" (which CLR is not doing here) was not made. Legislative "networks" described procedural, not substantive, activity. The jargon of Internal Revenue Code section 4942 (j) 
(3) (operating foundation) and the jargon of the technical sector (operations) were interpreted as being synonymous. And the word standard lost its identity altogether.

The irony is overwhelming. Like the old adage about the shoemaker's children who don't have shoes, it would appear that it is the information specialists who cannot communicate-Ruth L. Tighe, New England Library Information Network 